\title{
Primary small cell carcinoma of the esophagus: clinicopathological study of 44 cases
}

\author{
Wei-Wei Chen ${ }^{1 \dagger}$, Feng Wang ${ }^{1 \dagger}$, Dong-Sheng Zhang ${ }^{1}$, Hui-Yan Luo ${ }^{1}$, Zhi-Qiang Wang ${ }^{1}$, Feng-Hua Wang ${ }^{1}$, \\ Miao-Zhen Qiu', Chao Ren ${ }^{1}$, Xiao-Li Wei ${ }^{1}$, Wen-Jing Wu' ${ }^{1}$, Yu-Hong $\mathrm{Li}^{1}$ and Rui-Hua Xu
}

\begin{abstract}
Background: Primary small cell carcinoma of the esophagus (SCCE) is a highly aggressive disease characterized by early dissemination and poor prognosis. Because of the rarity of this disease, few previous studies have investigated the biomarkers associated with its prognosis. Leucine-rich repeat-containing G-protein coupled receptor 5 (Lgr5) is a stem cell marker and a member of the canonical Wnt-signaling cascade. However, the clinical role of Lgr5 in SCCE remains unknown.
\end{abstract}

Methods: Tissue sections were obtained from 44 patients diagnosed with SCCE and expression of Lgr5 was examined by immunohistochemistry. The correlations between Lgr5 expression, and clinical parameters and prognostic significance were evaluated.

Results: Lgr5 was expressed in SCCE cancer tissues. High Lgr5 expression was significantly correlated with lymph node metastasis $(p=0.003)$, late stage $(p=0.003)$ and unfavorable response to chemotherapy $(p=0.013)$ according to RECIST 1.0 criteria. Patients with higher Lgr5 expression levels had shorter overall survival times than those with lower expression levels.

Conclusions: These results demonstrated that overexpression of Lgr5 was significantly correlated with lymph node metastasis, tumor stage, and response to chemotherapy. Furthermore, high levels of Lgr5 expression appeared to be associated with poorer survival in patients with SCCE.

Keywords: Small cell carcinoma, Esophagus, Prognosis, Lgr5

\section{Background}

Esophageal carcinoma is one of the most common malignancies in China, but primary small cell carcinoma of the esophagus (SCCE) is a relatively rare histopathological type, accounting for only $1-2.8 \%$ of esophageal carcinomas $[1,2]$. SCCE is highly aggressive, and characterized by early dissemination and poor prognosis [3-10]. A total of 5,379 cases of esophageal cancer and 2,061 cases of small cell carcinoma were recorded at Sun Yat-sen University Cancer Center from 1994 to 2012, including 93 cases of SCCE. Little is known about the clinicopathological features of SCCE, and it is necessary to identify biomarkers for predicting prognosis and for distinguishing individuals with unfavorable prognoses.

\footnotetext{
* Correspondence: xurh@sysucc.org.cn

${ }^{\dagger}$ Equal contributors

${ }^{2}$ Department of Medical Oncology, Sun Yat-sen University Cancer Center, 651 Dong Feng Road East, Guangzhou 510060, China

Full list of author information is available at the end of the article
}

The Wnt signaling pathway is important for adult tissue maintenance. Perturbations in Wnt signaling cause human cancers [11]. Leucine-rich repeat-containing Gprotein coupled receptor 5 (Lgr5) is an orphan G-protein coupled receptor (GPCR) and a stem cell marker first described as a Wnt target gene [12]. It is also a member of the canonical Wnt-signaling cascade, which forms a signaling gradient in the intestinal crypt, thereby regulating cell proliferation and differentiation [13]. Lgr5 was also identified as a marker of poor prognosis in colon, ovary and liver cancers [14,15], and was considered to be involved in tumorigenesis in Barrett's esophagus and esophageal adenocarcinoma [16].

However, the expression and potential clinical significance of Lgr5 in SCCE has not been determined. In this study, we analyzed the expression levels of Lgr5 and their relationships with clinicopathological features in 44 patients with SCCE. 


\section{Methods}

Tumor tissues and patient information

A total of 44 paraffin-embedded samples were obtained from patients diagnosed with SCCE from January 11994 to January 12012 at Sun Yat-sen University Cancer Center. The diagnosis of SCCE had been confirmed by the Pathology Department of Sun Yat-sen University Cancer Center, based on the 2000 World Health Organization histological criteria for esophageal small cell carcinoma [17] and 2004 histological criteria for pulmonary small cell carcinoma [18]. As described previously [10], tumor cells were characterized by small, spindle-like, round or ovoid shape, scarce cytoplasm, indistinct cell borders, and an inconspicuous or absent nucleolus. Information on the neuroendocrine markers neuron-specific enolase (NSE), synaptophysin (Syn), chromogranin A (CgA) and CD56 were obtained from patient pathology reports. All patients were positive for CgA and/or Syn expression; about $70.5 \%$ of patients were Syn-positive, $84.1 \%$ were CgA-positive, $56.8 \%$ of cases were NSE-positive and 34.1\% were CD56-positive.

Informed consent was obtained from all patients and the study was approved by the Research Ethics Committee of Sun Yat-Sen University. No patients had received any treatment prior to surgery or biopsy. Of the 44 samples, 29 were obtained at surgery and 15 by biopsy. The clinicopathological records of all patients were reviewed. The American Joint Committee on Cancer (AJCC) clinical and pathologic staging system was adopted for all patients. Overall survival (OS) was defined as the time from the date of diagnosis to the point of death or the last follow-up.

Immunohistochemistry (IHC)

IHC was performed to study the expression of Lgr5 in SCCE tissues, as described previously [19]. Briefly, paraffin-embedded tissue sections were baked at $60^{\circ} \mathrm{C}$ for $2 \mathrm{~h}$, deparaffinized, and rehydrated. After treatment with 3\% hydrogen peroxide for $30 \mathrm{~min}$, the sections were put in a high-pressure environment for antigen retrieval. Tissue sections were incubated with rabbit anti-Lgr5 (1:400; Abcam, United states) overnight at $4^{\circ} \mathrm{C}$, then treated with anti-rabbit secondary antibody for $40 \mathrm{~min}$, followed by treatment with diaminobenzidine tetrahydrochloride (DAB), and counterstaining with hematoxylin. Human colon cancer tissues with strong Lgr5 staining were used as positive controls, based on previous reports [20]. Lgr5 immunostaining was evaluated by two independent observers who were blinded to the clinicopathological characteristics of the patients. Immunostaining scores were awarded by two independent observers according to the percentage and intensity of the stained cells. Positivity values were as follows: 0 (<10\%), 1 (10-25\%), 2 (25-50\%), $3(50-75 \%)$, and $4(>75 \%)$. Intensity values were as follows: 0 (negative), 1 (weak staining), 2 (moderate staining), and 3 (strong staining). The final score was calculated by multiplying the above two values. For subsequent

Table 1 Clinicopathological characteristics and Lgr5 expression in tumors from 44 patients with SCCE

\begin{tabular}{ccc}
\hline Variable & No.of patients & $\%$ \\
\hline Gender & 33 & 75.0 \\
Male & 11 & 25.0 \\
Female & & \\
Age & 15 & 34.1 \\
$>60$ & 29 & 65.9 \\
$<=60$ & & \\
PS score & 4 & 9.1 \\
$>1$ & 40 & 90.9 \\
$<=1$ & &
\end{tabular}

Tumor length(39 available)

$$
>=5 \mathrm{~cm}
$$

$<5 \mathrm{~cm}$

Tumor location

Upper thoracic segment

Middle thoracic segment

Lower thoracic segment

AJCC stage(43 available)

$$
\text { I/II }
$$

III/IV T classification(40 available)

$$
\mathrm{T}<=2
$$$$
\mathrm{T}>2
$$

N classification(42 available)

NO

N+

M classification(43 available)

$$
\text { Mo }
$$

Treatment approach

$$
\begin{gathered}
\text { Surgery } \\
\text { No } \\
\text { Yes }
\end{gathered}
$$

Chemotherapy

\begin{tabular}{ccc} 
No & 16 & 36.4 \\
Yes & 28 & 63.6 \\
Radiotherapy & & \\
No & 16 & 36.4 \\
Yes & 28 & 63.6 \\
Lgr5 expression & & \\
Low & 23 & 52.3 \\
High & 21 & 47.7 \\
\hline
\end{tabular}



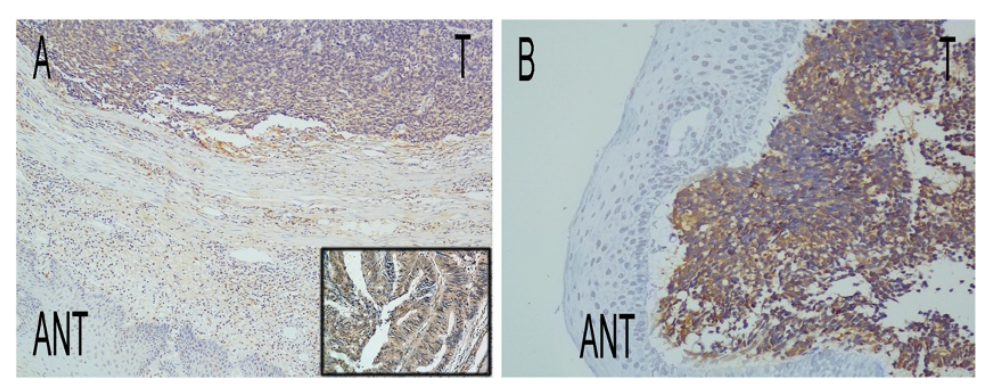

Figure 1 Immunohistochemical staining of Lgr5 in cancerous tissue and adjacent normal mucosa. A: Higher levels of Lgr5 expression were observed in tumor tissues compared with ANT ( $\times 100$ magnification). Colon cancer tissue was used as a positive control (insert). B: Higher levels of Lgr5 expression were observed in tumor tissues compared with ANT ( $\times 400$ magnification). Abbreviations: T: tumor, ANT: adjacent normal tissue.

Table 2 Correlation between clinicopathological characteristics and Lgr5 expression in patients with SCCE

\begin{tabular}{|c|c|c|c|}
\hline \multirow[b]{2}{*}{ Characteristics } & \multicolumn{2}{|c|}{ Lgr5 expression } & \multirow[b]{2}{*}{ Chi-square test $P$-value } \\
\hline & Low or none No. cases & High No. cases & \\
\hline Gender & & & .601 \\
\hline male & 18 & 15 & \\
\hline female & 5 & 6 & \\
\hline Age & & & .241 \\
\hline$>60$ & 6 & 9 & \\
\hline$<=60$ & 17 & 12 & \\
\hline Tumor length(39 available) & & & .256 \\
\hline$>=5 \mathrm{~cm}$ & 9 & 12 & \\
\hline$<5 \mathrm{~cm}$ & 11 & 7 & \\
\hline Tumor location & & & .721 \\
\hline Upper thoracic segment & 3 & 4 & \\
\hline Middle thoracic segment & 11 & 11 & \\
\hline Lower thoracic segment & 9 & 6 & \\
\hline AJCC stage(43 available) & & & .003 \\
\hline$|/| \mid$ & 15 & 4 & \\
\hline III/IV & 8 & 16 & \\
\hline T classification(40 available) & & & .206 \\
\hline$T<=2$ & 12 & 8 & \\
\hline$T>2$ & 8 & 12 & \\
\hline N classification(42 available) & & & .003 \\
\hline No & 13 & 3 & \\
\hline $\mathrm{N}+$ & 9 & 17 & \\
\hline M classification(43 available) & & & .329 \\
\hline MO & 19 & 14 & \\
\hline M1 & 4 & 6 & \\
\hline Chemotherapy response(19 available) & & & .013 \\
\hline Reached CR/PR & 5 & 1 & \\
\hline Did not reach CR/PR & 3 & 10 & \\
\hline
\end{tabular}




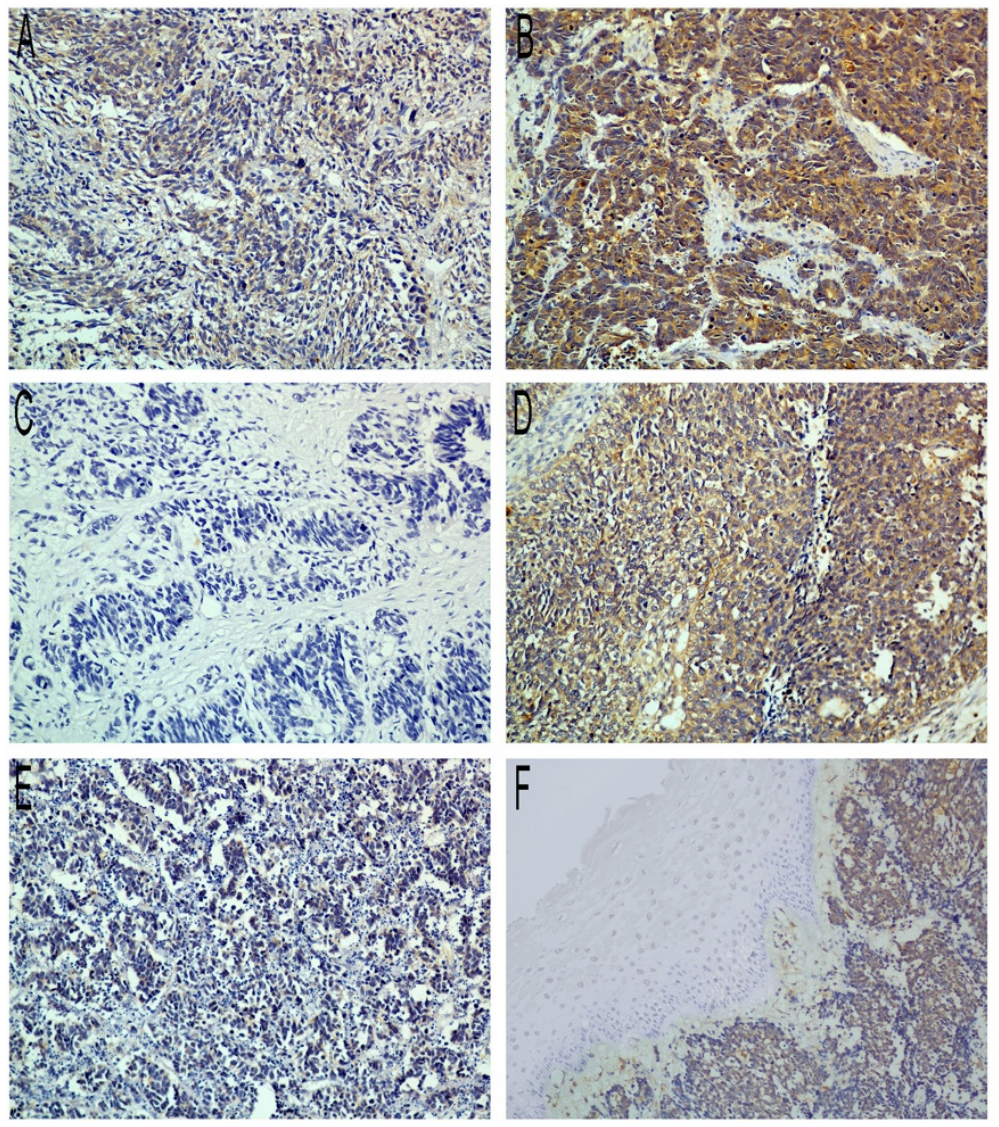

Figure $\mathbf{2}$ Immunohistochemical staining of Lgr5 in small cell carcinoma of the esophagus ( $\times \mathbf{4 0 0}$ magnification). A: Lgr5 expression in stage I patients (representative slide). B: Lgr5 expression in stage IV patients (representative slide). C: Lgr5 expression in patients without lymph node metastasis (representative slide). D: Lgr5 expression in patients with lymph node metastasis (representative slide). E: Lgr5 expression in patients who achieved complete response during chemotherapy (representative slide). F: Lgr5 expression in patients evaluated with progressive disease during chemotherapy (representative slide).

analysis, high expression was defined as a final score $>4$ and low expression was a score $\leq 4$.

\section{Statistical analysis}

Statistical analysis was carried out using SPSS 16.0. The significance of correlations between biomarker expression levels and clinical features were calculated using $\chi^{2}$ tests. Survival curves were displayed by Kaplan-Meier analysis and differences in survival were assessed by logrank tests. A two-sided $\alpha$-error of less than $5 \%(\mathrm{p}<0.05)$ was considered as statistically significant.

\section{Results}

\section{Expression of Lgr5 in SCCE and correlation between} expression and clinicopathologic features

Detailed information was collected for 44 patients (Table 1). The median follow-up time for all patients was 11.1 months (3-84.9 months). Tissue sections were subjected to IHC to investigate Lgr5 expression levels and to correlate these with clinicopathological features.
Lgr5 was localized mainly in the cytoplasm of cancer cells (Figure 1). Adjacent normal esophageal tissue (ANT) was available from five patients, two of whom showed higher Lgr5 expression levels in tumor tissues than in ANT (representative slide shown in Figure 1). According to the IHC scoring system, $47.7 \%$ of tumors showed high cytoplasmic expression of Lgr5. High Lgr5 expression levels were significantly correlated with lymph node metastasis $(\mathrm{p}=0.003)$, late stage $(\mathrm{p}=0.003)$ and unfavorable response to chemotherapy ( $\mathrm{p}=0.013$ ) according to RECIST 1.0 criteria (Table 2, representative slides shown in Figure 2). However, Lgr5 expression was not correlated with sex, age, tumor type, tumor location, tumor length or distant metastases.

\section{Association between Lgr5 expression and patient survival} High expression of Lgr5 was associated with a shorter overall survival time (Figure $3, \mathrm{p}=0.001$ ). The overall 1-, 2 -, and 5-year cumulative survival rates in patients with high expression levels of Lgr5 were $20 \%, 0 \%$, and $0 \%$, 


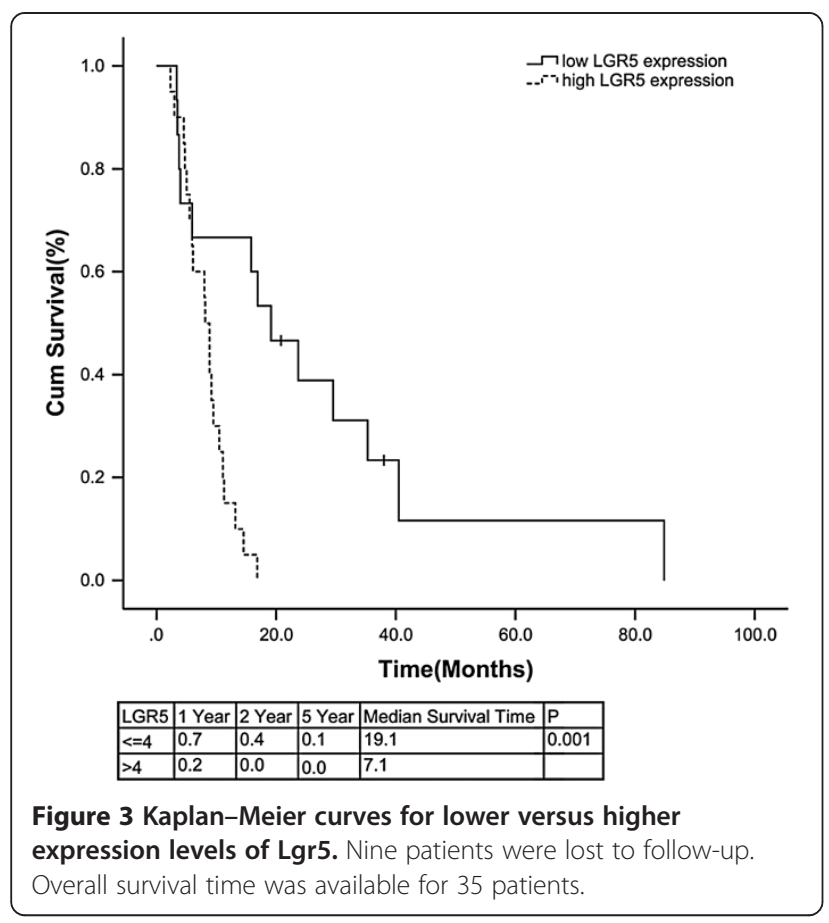

respectively, compared with $70 \%, 40 \%$, and $10 \%$ in patients with low Lgr5 expression. Cox regression analysis identified tumor length $(\mathrm{p}=0.043)$, lymph node involvement $(\mathrm{p}=0.04)$ and chemotherapy $(\mathrm{p}=0.006)$ as independent prognostic factors (Table 3 ).

\section{Discussion}

SCCE is a highly metastatic disease with a median survival time of less than 1 year [21]. The recurrence rate after surgery is very high, even in patients with earlystage disease [22]. However, the aggressive features and poor prognosis of SCCE found in clinical practice have not yet been linked to any specific biomarkers. Recent genetic discoveries based on tumor genome sequencing suggest that the Wnt pathway plays important roles in tumor biology [23]. Activation of the Wnt pathway releases $\beta$-catenin, which interacts with $\mathrm{T}$ cell factor family members to activate the transcription of downstream target genes [24]. R-spondins potently enhance $\beta$-catenin signaling and have been implicated in human disease and malignancy $[25,26]$. Lgr5 is a receptor for R-spondin and was shown to activate $\beta$-catenin signaling when bound to R-spondins $[25,27,28]$, and may be associated with tumorigenesis via the Wnt pathway.

Iuga et al. [29] reported that Lgr5 was a novel IHC marker for gastrointestinal neuroendocrine tumors; $88 \%$ of primary neuroendocrine tumors and $87 \%$ of metastases stained positive for cytoplasmic Lgr5. Moreover, Lgr5 stained positive in most cases expressing CgA and Syn (34/38). These findings were consistent with our study, which also found high Lgr5 expression levels in
Table 3 Univariate and multivariate analyses of prognostic parameters in patients with SCCE

\begin{tabular}{|c|c|c|c|c|c|c|}
\hline \multirow{3}{*}{$\frac{\text { Variable }}{\text { Tumor length }}$} & \multicolumn{2}{|c|}{ Univariate analysis } & \multicolumn{4}{|c|}{ Multivariate analysis } \\
\hline & \multirow[t]{2}{*}{ No. } & \multirow{2}{*}{$\begin{array}{c}\mathbf{P} \\
.045\end{array}$} & \multirow{2}{*}{$\begin{array}{l}\mathbf{H R} \\
.288\end{array}$} & \multicolumn{2}{|c|}{$95.0 \% \mathrm{Cl}$} & \multirow{2}{*}{$\begin{array}{c}\mathbf{p} \\
.043\end{array}$} \\
\hline & & & & .086 & .963 & \\
\hline$>=5 \mathrm{~cm}$ & 21 & & & & & \\
\hline$<5 \mathrm{~cm}$ & 18 & & & & & \\
\hline Lgr5 expression & & .001 & 1.519 & .346 & 6.659 & .580 \\
\hline Low & 23 & & & & & \\
\hline High & 21 & & & & & \\
\hline T classification & & .725 & .760 & .276 & 2.090 & .595 \\
\hline$T<=2$ & 20 & & & & & \\
\hline $\mathrm{T}>2$ & 20 & & & & & \\
\hline N classification & & .170 & 3.726 & 1.063 & 13.061 & .040 \\
\hline No & 16 & & & & & \\
\hline $\mathrm{N}+$ & 26 & & & & & \\
\hline M classification & & .096 & 4.861 & .902 & 26.212 & .066 \\
\hline MO & 33 & & & & & \\
\hline M1 & 10 & & & & & \\
\hline Chemotherapy & & .088 & .229 & .081 & .649 & .006 \\
\hline No & 16 & & & & & \\
\hline Yes & 28 & & & & & \\
\hline Surgery & & .207 & 1.222 & .257 & 5.822 & .801 \\
\hline No & 11 & & & & & \\
\hline Yes & 33 & & & & & \\
\hline
\end{tabular}

SCCEs, which were rich in CgA and Syn. von Rahden et al. [16] reported LgR5 expression in 35 of 41 (85\%) patients with esophageal adenocarcinomas with Barrett's esophagus, and in 16 of 19 (81\%) without Barrett's esophagus. Becker et al. [30] also detected Lgr5 expression in early esophageal squamous cells. Based on the above findings, we examined Lgr5 expression in SCCE.

Of the 44 patients with SCCE examined by IHC, only $15.8 \%$ who presented with high levels of Lgr5 survived for longer than 1 year after diagnosis (data not shown). The median survival in patients with high expression levels of Lgr5 was 7 months, which was 11 months shorter than in patients with lower expression of Lgr5. Less than $20 \%$ of patients (18 patients) had survived longer than 2 years at the end of follow-up, none of whom presented with high Lgr5 expression. Our results indicated that high levels of Lgr5 expression were significantly correlated with lymph node metastasis and late stage (stage III/IV), suggesting that high expression of Lgr5 might predict a poor prognosis. Indeed $62 \%$ of patients with lymph node metastases failed to survive for longer than 1 year, in accordance with a previous study in which esophageal cancer patients with more than four involved lymph nodes showed similar survival to 
patients with M1 disease [31]. In Cox regression analysis, lymph node involvement was an independent prognostic factor, which might explain the association between high expression of Lgr5 and poor prognosis.

SCCE is a systemic disease [21]. Chemotherapy provides the backbone of SCCE therapy [21,32], which was in accordance with the fact that chemotherapy was an independent prognostic factor in the present study. Lgr5 expression may also predict response to chemotherapy in SCCE. High Lgr5 expression was significantly correlated with unfavorable response in this study; only $33 \%$ of patients with high expression achieved partial/ complete responses during chemotherapy. Additionally, Lgr5 may also predict chemotherapy response in colorectal cancer [33].

A recent study suggested that GPCRs and their signal transduction pathways may provide promising new therapeutic approaches [34]. They are involved in the control of blood pressure, maintenance of kidney function, occurrence of neurological diseases and the progression of cancer [34]. Approximately $36 \%$ of currently-marketed drugs target GPCRs [35]. Lgr5 has been suggested to be involved in cancer progression through regulation of the Wnt signaling pathway $[25,27,28]$. Lgr5 knockdown was shown to induce cell death [36], and furthermore, a recentlydeveloped monoclonal antibody (KM4056) was reported to have potent complement-dependent cytotoxicity activity in vitro, and to show strong anti-tumor activity in vivo [37]. Lgr5 thus remains a potential for targeted therapy.

Overall, the results of this study suggest that Lgr5 protein expression may represent a possible prognostic marker in SCCE patients. However, these results need to be validated by further studies with larger sample sizes and in randomized patient cohorts before Lgr5 IHC can be used in clinical applications.

\section{Conclusions}

In summary, overexpression of Lgr5 was significantly correlated with lymph node metastasis, tumor stage and response to chemotherapy, while high levels of Lgr5 expression were also associated with poor survival in patients with SCCE.

\footnotetext{
Abbreviations

SCCE: Primary small cell carcinoma of esophagus; GPCR: Orphan G-protein coupled receptor; AJCC: American Joint Committee on Cancer; OS: Overall survival; ANT: Adjacent normal tissue.
}

\section{Competing interests}

The authors declare that they have no competing interests.

\section{Authors' contributions}

WC, FW carried out the immunohistochemistry staining and drafted the manuscript. WC, FW, DZ, HL, ZW' FW, MQ, CR, XW and WW participated in the design of the study and performed the statistical analysis. WC, FW, YL and RX conceived of the study, and participated in its design and coordination and helped to draft the manuscript. All authors read and approved the final manuscript.

\section{Acknowledgements}

We thank Shu-Mei Yan and Mu-Yan Cai for diagnosis confirmation and Yu Chen for editorial assistance. This work was supported by the National High Technology Research and Development Program of China (863 Program), China (No.2012AA02A506); Science and Technology Department of Guangdong Province, China (No. 2012B031800088); Medical Scientific Research Foundation of Guangdong Province, China (No.C2011019).

\section{Author details}

${ }^{1}$ Department of Medical Oncology and State Key Laboratory of Oncology in South China, Sun Yat-sen University Cancer Center, Guangzhou, China.

${ }^{2}$ Department of Medical Oncology, Sun Yat-sen University Cancer Center, 651 Dong Feng Road East, Guangzhou 510060, China.

Received: 4 September 2013 Accepted: 19 March 2014

Published: 25 March 2014

\section{References}

1. Kim JH, Lee SH, Park J, Kim HY, Lee SI, Nam EM, Park JO, Kim K, Jung CW, Im YH, Kang WK, Lee MH, Park K: Extrapulmonary small-cell carcinoma: a single-institution experience. Jpn J Clin Oncol 2004, 34(5):250-254.

2. Ku GY, Minsky BD, Rusch WW, Bains M, Kelsen DP, Ilson DH: Small-cell carcinoma of the esophagus and gastroesophageal junction: review of the Memorial Sloan-Kettering experience. Ann Oncol 2008, 19(3):533-537.

3. Nichols GL, Kelsen DP: Small cell carcinoma of the esophagus. The Memorial Hospital experience 1970 to 1987. Cancer 1989, 64(7):1531-1533.

4. Huncharek M, Muscat J: Small cell carcinoma of the esophagus. The Massachusetts General Hospital experience, 1978 to 1993. Chest 1995, 107(1):179-181.

5. Nishimaki T, Suzuki T, Nakagawa S, Watanabe K, Aizawa K, Hatakeyama K: Tumor spread and outcome of treatment in primary esophageal small cell carcinoma. J Surg Oncol 1997, 64(2):130-134.

6. Lam KY, Law S, Tung PH, Wong J: Esophageal small cell carcinomas: clinicopathologic parameters, p53 overexpression, proliferation marker, and their impact on pathogenesis. Arch Pathol Lab Med 2000, 124(2):228-233.

7. Pantvaidya GH, Pramesh CS, Deshpande MS, Jambhekar NA, Sharma S, Deshpande RK: Small cell carcinoma of the esophagus: the Tata Memorial Hospital experience. Ann Thorac Surg 2002, 74(6):1924-1927.

8. Hosokawa A, Shimada Y, Matsumura Y, Yamada Y, Muro K, Hamaguchi T, Igaki H, Tachimori Y, Kato H, Shirao K: Small cell carcinoma of the esophagus. Analysis of 14 cases and literature review. Hepatogastroenterology 2005, 52(66):1738-1741.

9. Yau KK, Siu WT, Wong DC, Chau CH, Li AC, Law BK, Li MK: Non-operative management of small cell carcinoma of esophagus. Dis Esophagus 2007, 20(6):487-490.

10. Yun JP, Zhang MF, Hou JH, Tian QH, Fu J, Liang XM, Wu QL, Rong TH: Primary small cell carcinoma of the esophagus: clinicopathological and immunohistochemical features of 21 cases. BMC Cancer 2007, 7:38.

11. Nusse R: Wnt signaling in disease and in development. Cell Res 2005, 15(1):28-32.

12. Van der Flier LG, Sabates-Bellver J, Oving I, Haegebarth A, De Palo M, Anti M, Van Gijn ME, Suijkerbuijk S, Van de Wetering M, Marra G, Clevers H: The Intestinal Wnt/TCF Signature. Gastroenterology 2007, 132(2):628-632.

13. Reya T, Clevers H: Wnt signalling in stem cells and cancer. Nature 2005, 434(7035):843-850.

14. McClanahan T, Koseoglu S, Smith K, Grein J, Gustafson E, Black S, Kirschmeier P, Samatar AA: Identification of overexpression of orphan G protein-coupled receptor GPR49 in human colon and ovarian primary tumors. Cancer Biol Ther 2006, 5(4):419-426.

15. Yamamoto Y, Sakamoto M, Fujii G, Tsuiji H, Kenetaka K, Asaka M, Hirohashi S: Overexpression of orphan G-protein-coupled receptor, Gpr49, in human hepatocellular carcinomas with beta-catenin mutations. Hepatology 2003, 37(3):528-533.

16. von Rahden BH, Kircher S, Lazariotou M, Reiber C, Stuermer L, Otto C, Germer CT, Grimm M: LgR5 expression and cancer stem cell hypothesis: clue to define the true origin of esophageal adenocarcinomas with and without Barrett's esophagus? J Exp Clin Cancer Res 2011, 30:23. 
17. Capella C, Solcia E, Sobin L, Arnold R: Endocrine Tumours of the Oesophagus. In World Health Organization Classification of Tumors, Pathology \& Genetics, Tumors of the Digestive System. Edited by Stanley R, Hamilton LAA. Lyon: IARC Press; 2000:26-27.

18. Travis W, Petersen I, Nicholson S, Meyerson M, Hirsch F, Hanash S, Pugatch B, Jen J, Geisinger K, Takahashi T, Brambilla E, Fernandez E, Gazdar A, Capron F: Small Cell Carcinoma. In World Health Organization Classification of Tumors, Pathology \& Genetics, Tumors of the Lung, Pleura, Thymus and Heart. Edited by Travis WD, Brambilla E, Konrad Müller-Hermelink H, Harris CC. Lyon: IARC Press; 2004:31-34

19. Zeng ZL, Wu WJ, Yang J, Tang ZJ, Chen DL, Qiu MZ, Luo HY, Wang ZQ, Jin Y, Wang DS, Xu RH: Prognostic relevance of melanoma antigen D1 expression in colorectal carcinoma. J Trans/ Med 2012, 10:181.

20. Ziskin JL, Dunlap D, Yaylaoglu M, Fodor IK, Forrest WF, Patel R, Ge N, Hutchins GG, Pine JK, Quirke P, Koeppen H, Jubb AM: In situ validation of an intestinal stem cell signature in colorectal cancer. Gut 2013, 62(7):1012-1023.

21. LV J, Liang J, Wang J, Wang L, He J, Xiao Z, Yin W: Primary small cell carcinoma of the esophagus. J Thorac Oncol 2008, 3(12):1460-1465.

22. Nemoto K, Zhao HJ, Goto T, Ogawa Y, Takai Y, Matsushita H, Takeda K, Takahashi C, Saito H, Yamada S: Radiation therapy for limited-stage small-cell esophageal cancer. Am J Clin Oncol 2002, 25(4):404-407.

23. Polakis P: Wnt signaling in cancer. Cold Spring Harb Perspect Biol 2012, 4(5). doi: 10.1101/cshperspect.a008052.

24. Korinek V, Barker N, Morin PJ, van Wichen D, de Weger R, Kinzler KW, Vogelstein B, Clevers $\mathrm{H}$ : Constitutive transcriptional activation by a beta-catenin-Tcf complex in APC-/- colon carcinoma. Science 1997, 275(5307):1784-1787.

25. Kazanskaya O, Glinka A, del Barco BI, Stannek P, Niehrs C, Wu W: R-Spondin2 is a secreted activator of Wnt/beta-catenin signaling and is required for Xenopus myogenesis. Dev Cell 2004, 7(4):525-534.

26. Parma P, Radi O, Vidal V, Chaboissier MC, Dellambra E, Valentini S, Guerra L, Schedl A, Camerino G: R-spondin 1 is essential in sex determination, skin differentiation and malignancy. Nat Genet 2006, 38(11):1304-1309.

27. Kim KA, Wagle M, Tran K, Zhan X, Dixon MA, Liu S, Gros D, Korver W, Yonkovich S, Tomasevic N, Binnerts M, Abo A: R-Spondin family members regulate the Wnt pathway by a common mechanism. Mol Biol Cell 2008, 19(6):2588-2596

28. Nam JS, Turcotte TJ, Smith PF, Choi S, Yoon JK: Mouse cristin/R-spondin family proteins are novel ligands for the Frizzled 8 and LRP6 receptors and activate beta-catenin-dependent gene expression. J Biol Chem 2006, 281(19):13247-13257.

29. luga AC: Analysis of LGR5 Immunohistochemical Expression in Gastrointestinal Neuroendocrine Tumors. 2012. Unpublished poster presentation at United Stats and Canadian Academy of Pathology Conference 2012, March 21, 2012

30. Becker L, Huang Q, Mashimo H: Immunostaining of Lgr5, an intestinal stem cell marker, in normal and premalignant human gastrointestinal tissue. Sci World J 2008, 8:1168-1176.

31. Rizk N, Venkatraman E, Park B, Flores R, Bains MS, Rusch V: The prognostic importance of the number of involved lymph nodes in esophageal cancer: implications for revisions of the American Joint Committee on Cancer staging system. J Thorac Cardiovasc Surg 2006, 132(6):1374-1381.

32. Meng MB, Zaorsky NG, Jiang C, Tian LJ, Wang HH, Liu CL, Wang J, Tao Z, Sun Y, Pang QS, Zhao LJ, Yuan ZY, Ping W: Radiotherapy and chemotherapy are associated with improved outcomes over surgery and chemotherapy in the management of limited-stage small cell esophageal carcinoma. Radiother Oncol 2013, 106(3):317-322.

33. Hsu HC, Liu YS, Tseng KC, Hsu CL, Liang Y, Yang TS, Chen JS, Tang RP, Chen SJ, Chen HC: Overexpression of Lgr5 correlates with resistance to 5-FU-based chemotherapy in colorectal cancer. Int J Colorectal Dis 2013, 28:1535-46.

34. Luo J, Zhou W, Zhou X, Li D, Weng J, Yi Z, Cho SG, Li C, Yi T, Wu X, Li XY, de Crombrugghe B, Hook M, Liu M: Regulation of bone formation and remodeling by G-protein-coupled receptor 48. Development 2009, 136(16):2747-2756.

35. Rask-Andersen M, Almen MS, Schioth HB: Trends in the exploitation of novel drug targets. Nat Rev Drug Discov 2011, 10(8):579-590.
36. Al-Kharusi MR, Smartt HJ, Greenhough A, Collard TJ, Emery ED, Williams AC, Paraskeva C: LGR5 promotes survival in human colorectal adenoma cells and is upregulated by PGE2: implications for targeting adenoma stem cells with NSAIDs. Carcinogenesis 2013, 34(5):1150-1157.

37. Sasaki Y, Kosaka H, Usami K, Toki H, Kawai H, Shiraishi N, Ota T, Nakamura K, Furuya A, Satoh M, Hasegawa K, Masuda K: Establishment of a novel monoclonal antibody against LGR5. Biochem Biophys Res Commun 2010, 394(3):498-502.

doi:10.1186/1471-2407-14-222

Cite this article as: Chen et al:: Primary small cell carcinoma of the esophagus: clinicopathological study of 44 cases. BMC Cancer 2014 14:222

\section{Submit your next manuscript to BioMed Central and take full advantage of:}

- Convenient online submission

- Thorough peer review

- No space constraints or color figure charges

- Immediate publication on acceptance

- Inclusion in PubMed, CAS, Scopus and Google Scholar

- Research which is freely available for redistribution

Submit your manuscript at www.biomedcentral.com/submit
C) Biomed Central 